\title{
Effects of acute hemorrhage on intrapulmonary shunt in a pig model of acute respiratory distress-like syndrome
}

\author{
Nils Siegenthaler ${ }^{1,2}$, Raphael Giraud ${ }^{1,2}$, Delphine S. Courvoisier ${ }^{3}$, Claes U. Wiklund ${ }^{4}$ and Karim Bendjelid ${ }^{1,2,5,6^{*}}$
}

\begin{abstract}
Background: In acute respiratory distress syndrome (ARDS), gas exchange and respiratory system mechanics (compliance) are severely impaired. Besides ventilatory parameters, the degree of respiratory abnormality can be influenced by the circulatory state. This study investigated the influence of acute hypovolemia on the respiratory system.

Methods: We performed a secondary analysis of a previous study including 8 pigs with ARDS-like syndrome induced by lung lavage and surfactant depletion method (ARDS group) and 10 mechanically ventilated pigs with no intervention (CTRL group). Animals of both groups were subjected to hemorrhage and retransfusion successively. We reanalyzed the effect of acute blood volume variations on intrapulmonary shunt (shunt), arterial oxygenation $\left(\mathrm{PaO}_{2}: \mathrm{FiO}_{2}\right)$, global oxygen delivery $\left(\mathrm{DO}_{2}\right)$ and respiratory system compliance (Crs).

Results: In the ARDS group, after hemorrhage, shunt decreased $(-28+/-3.5 \%(p<0.001))$, respiratory system compliance (Crs) increased $(+5.1+/-1.0 \mathrm{ml} / \mathrm{cm} \mathrm{H} 2 \mathrm{O}(p<0.001))$ moreover, there was a concurrent increase in PaO2:FiO2 $(+113+/-19.1 \mathrm{mmHg} ; p<0.001)$ but this did not prevent a reduction in $\mathrm{DO}_{2}(-317+/-49.8 \mathrm{ml} / \mathrm{min}$; $p<0.001)$. Following retransfusion, shunt and Crs return towards pre-hemorrhage values. Similar changes, but of smaller magnitude were observed in the CTRL group, except that no significant changes in oxygenation occurred.

Conclusions: The present analysis suggests that an acute decrease in blood volume results in a decrease in shunt with a parallel improvement in arterial oxygenation and an increase in Crs during ARDS-like syndrome. Our results strengthen the importance to integrate the circulatory condition in the analysis of the state of the respiratory system. However, the translation of this physiological model in a clinical perspective is not straightforward because our model of acute and severe hemorrhage is not strictly equivalent to a progressive hypovolemia, as could be obtained in ICU by diuretic. Furthermore, the present model does not consider the impact of blood loss induced decrease of $\mathrm{DO}_{2}$ on other vital organs function.
\end{abstract}

Trial registration: 'Not applicable'.

Keywords: Transpulmonary blood flow, Lung compliance, Admission

\section{Background}

Several studies explored the influence of ventilation parameters during acute respiratory distress syndrome (ARDS) $[1,2]$. However, the influence of hemodynamic parameters on respiratory characteristics is frequently neglected. Indeed, animal studies reported that a decrease in cardiac output $(\mathrm{CO})$, induced by a reduction

\footnotetext{
* Correspondence: karim.bendjelid@hcuge.ch

'Intensive Care Unit, University Hospitals of Geneva, Geneva, Switzerland

2University of Geneva, University Medical Center, Geneva, Switzerland

Full list of author information is available at the end of the article
}

in blood volume [3-5] or by pharmacological intervention $[6,7]$, may be associated with a decrease in intrapulmonary shunt, in normal lung $[3,5]$ as well as during ARDS $[3,4,6,7]$. In addition, other studies reported an increase in intrapulmonary shunt associated with an increase in $\mathrm{CO}[5,8]$. Human studies reported similar results, where a parallel change in $\mathrm{CO}$ and shunt has been observed in normal subjects during exercise [9] or during $\mathrm{CO}$ reduction following the use of positive end-expiratory pressure (PEEP) in patients with ARDS [10], even if the effect of PEEP on shunt is not only 
related to his effect on $\mathrm{CO}$ [11]. Concerning the respiratory system compliance (Crs), previous studies reported conflicting results as some observed an increase [12, 13], a decrease [5] or no significant changes [14, 15] in Crs related to hemorrhage. On the other hand, an increase in pulmonary blood volume has been shown to result in a decrease in lung compliance [16].

In a previous study exploring the influence of tidal volume $\left(\mathrm{V}_{\mathrm{T}}\right)$ and respiratory rate $(\mathrm{RR})$ on pulse pressure variations in pigs with ARDS [17], we observed an unexpected improvement in oxygenation and an increase in Crs during acute hemorrhage. In order to complete previous studies on this issue, we analyzed retrospectively our data with the hypothesis that a decrease in $\mathrm{CO}$ due to hypovolemia, may decrease intrapulmonary shunt, improve Crs and may result in an improvement in arterial oxygenation during ARDS.

\section{Methods}

The present study was a second analysis from a previous study [17]. The initial experimentation was performed on 24 domestic pigs. Domestic pigs were selected for the experiment because of their strong similarity in term of physiologic values, hemodynamic and respiratory behavior with humans. In this first analysis only 16 animals have been included as 8 pigs were excluded. Indeed, five animals allowed to improve the model (among them 2 animals died during the experiment), and three animals were excluded because of technical problems (dysfunction of the measurement systems). For the present analysis, 18 animals (mean weight of $31.4 \pm 3.1 \mathrm{~kg}$ ) from the $24 \mathrm{con}$ sidered in the first study have been included. Four pigs were excluded due to lack of data needed for the present analysis and two other animals died during the experiment.

\section{Ethics statement}

The study was approved by the Ethics Committee for Animal Research at the University Medical Centre and by the Cantonal Veterinary Office of Geneva, Switzerland (No 31.1.1043/3127/1). Animals received respectful care in accordance with the Guide for the Care and Use of Laboratory Animals (Institute of Laboratory Animal Resources, 1996).

\section{Preparation}

Animals were premedicated with intramuscular azaperon $6 \mathrm{mg} \mathrm{kg}{ }^{-1}$, midazolam $0.5 \mathrm{mg} \cdot \mathrm{kg}^{-1}$, and atropine $0.5 \mathrm{mg}$. Anesthesia was induced by isoflurane and maintained by fentanyl $20 \mu \mathrm{g} \cdot \mathrm{kg}^{-1} \cdot \mathrm{h}^{-1}$, isoflurane $1.5-2.0 \%$ and pancuronium $0.4 \mathrm{mg} \cdot \mathrm{kg}^{-1} \cdot \mathrm{h}^{-1}$. Animals were intubated and mechanically ventilated (Servo Ventilator 900, Siemens-Elema, Sweden). $\mathrm{FiO}_{2}$ was set at 0.4 for the control (CTRL) group and 1.0 for the ARDS group. Tidal volume $\left(\mathrm{V}_{\mathrm{T}}\right)$ was set at
$10 \mathrm{ml} . \mathrm{kg}^{-1}$ without positive end expiratory pressure (PEEP) and respiratory rate (RR) was $15 / \mathrm{min}$ with a fixed inspiratory to expiratory time ratio (1:2). A SwanGanz catheter (CCOmboV, 7.5 F, Edwards Lifesciences ${ }^{\mathrm{Tw}}$, Irvine, CA) was placed in the pulmonary artery. Arterial pressure was recorded in the aorta trough a carotid arterial catheter. A right internal jugular vein catheter was placed for central venous pressure (CVP) measurement, drug infusion and blood retransfusion. Heart rate and rhythm were recorded with a standard 3-lead electrocardiogram.

\section{Measurements \\ Respiratory system compliance}

Airway pressure was monitored (UltimaTM, Datex/ Instrumentarium, Helsinki, Finland). $V_{T}$ was calculated by digital integration of a flow signal measured by a pneumotachograph (Gould Godart, model 17212). Quasistatic Crs was calculated after an inspiratory pause of $3 \mathrm{~s}$ as $\mathrm{V}_{\mathrm{T}} /$ (plateau airway pressure - PEEP). Flow tracings were visually checked to ensure the absence of signs of intrinsic PEEP [18].

\section{Blood gas tensions}

Arterial blood gas (ABG) tensions, hemoglobin ( $\mathrm{Hb})$, oxygen saturation (arterial blood oxygen saturation $\left(\mathrm{SaO}_{2}\right)$ and mixed venous blood oxygen saturation $\left(\mathrm{SvO}_{2}\right)$ were analyzed by an automated oximeter (ABL-505 Analyzer, Radiometer, Copenhagen, Denmark).

\section{Intrapulmonary shunt}

In the ARDS group, shunt was calculated using the standard formula: Qs/Qt $=\left(\mathrm{CcO}_{2}-\mathrm{CaO}_{2}\right) /\left(\mathrm{CcO}_{2}-\mathrm{CvO}_{2}\right)$ with the $\mathrm{FiO}_{2}$ set at 1.0.

In the present equation, Qs represents the shunt flow; Qt represents the systemic blood flow, the $\mathrm{CcO}_{2}$ represents the pulmonary capillary oxygen content; $\mathrm{CaO}_{2}$, the arterial oxygen content and $\mathrm{CvO} 2$, the mixed venous oxygen content. Oxygen content in arterial venous and capillary blood where calculated as: $(1.34 \times$ oxygen blood saturation $\times$ hemoglobin $[\mathrm{Hb}])-\left(\mathrm{PO}_{2} \times 0.003\right)$. In the CTRL group, as $\mathrm{FiO}_{2}$ was set at 0.4 therefore, the calculation of shunt represent venous admixture.

\section{Global oxygen delivery}

$\mathrm{DO}_{2}$ was calculated as the product of $\mathrm{CaO}_{2}$ and $\mathrm{CO}$, where $\mathrm{CaO}_{2}$ was calculated as $1.34 \times \mathrm{Hb} \times \mathrm{SaO}_{2}+$ $\left(0.003 \times \mathrm{PaO}_{2}\right)$.

Hemodynamic and respiratory measurements were digitized using an analog/digital interface converter (Biopac, Santa Barbara, CA, USA) and stored for offline analysis. 


\section{Experimental protocol}

Animals were separated into two groups. The CTRL group $(n=10)$ received anesthesia and controlled mechanical ventilation but no intervention. The ARDS group $(n=8)$ was submitted to a procedure of surfactant depletion to induce an ARDS-like syndrome [19]. This procedure consisted of lung lavage with $\mathrm{NaCl} 0.9 \%$ $(1000 \mathrm{ml})$ at $37{ }^{\circ} \mathrm{C}$ repeated until criteria for ARDS were fulfilled $\left(\mathrm{PaO}_{2} / \mathrm{FiO}_{2}<200 \mathrm{mmHg}\right)$. This required a mean $\pm \mathrm{SD}$ of $3.1 \pm 0.3$ lung lavage at $12.6 \pm 3.5 \mathrm{~min}$ intervals.

During hemorrhage total blood volume was reduced by $40 \%$ of (estimated at $70 \mathrm{ml} . \mathrm{kg}^{-1}$ body weight) over 5$10 \mathrm{~min}$. Removed blood was stored at body temperature in bags containing citrate-phosphate-dextrose (Baxter AG, Volketswil, Switzerland) and was totally retransfused during the retransfusion period. The mean time between the start of bleeding until completed retransfusion was $49 \pm 11 \mathrm{~min}$.

Measurement were assessed at pre-hemorrhage, hemorrhage, and retransfusion period in the CTRL group and at baseline (pre-ARDS), pre-hemorrhage (post-ARDS), hemorrhage and retransfusion in the ARDS group. As the original study was designed to investigate the influence of $V_{T}$ and $R R$ on pulse pressure variations, three variants of ventilation were used successively during each period: $\mathrm{V} 1=\mathrm{V}_{\mathrm{T}} 10 \mathrm{ml} \cdot \mathrm{kg}^{-1}$ and RR $15 \mathrm{~min}^{-1} ; \mathrm{V} 2=\mathrm{V}_{\mathrm{T}} 6 \mathrm{ml} \cdot \mathrm{kg}^{-1}$ and RR $25 \mathrm{~min}^{-1}$; and $\mathrm{V} 3=\mathrm{V}_{\mathrm{T}} 6 \mathrm{ml} . \mathrm{kg}^{-1}$ and RR $15 \mathrm{~min}^{-1}$ (5-7 min each).

\section{Statistical analysis}

Data are presented as mean \pm SD or as mean changes between periods $\pm \mathrm{SE}$. Baseline measures (pre-ARDS) in the ARDS group were not included in the statistical analyses. To determine the influence of hemorrhage on measured variables, we used a mixed effects analysis of variance (ANOVA) with fixed effect for the 3 periods of the experiment and random effect for pig (8 or 10). The same model was used to analyze the changes of the major determinants of $\mathrm{DO}_{2}\left(\mathrm{CaO}_{2}, \mathrm{Hb}\right.$ and $\left.\mathrm{SaO}_{2},\right)$ in the ARDS group only. This statistical model estimates all comparisons between time periods simultaneously, reducing the risk of type I error. Furthermore, it takes into account repeated measurements of each pig across periods and across variants of ventilation. We determined the significance of the effect of hemorrhage and retransfusion on these parameters. As the goal of the analysis was to determine the effect of acute hemorrhage on shunt and Crs and because in the CTRL group venous admixture rather than true shunt was estimated, we did not compare the two groups of animals. Results are presented as the mean difference between two periods (hemorrhage vs prehemorrhage; retransfusion vs hemorrhage; retransfusion vs prehemorrhage) with respective $p$ values. Because $\mathrm{SvO}_{2}$ may influence $\mathrm{PaO}_{2}: \mathrm{FiO}_{2}$ through venous admixture [20] we also analyzed $\mathrm{PaO}_{2}: \mathrm{FiO}_{2}$ adjusted for $\mathrm{SvO}_{2}$. After visual inspection of the data in order to determine the effect of successive ventilation mode on shunt in the ARDS group, we performed a mixed effects analysis of variance of the shunt across variant of ventilation. Comparison of blood loss between the CTRL group and the ARDS group were performed using unpaired $t$-test. All analyses were performed with $\mathrm{R}$ software (Version 2.15.1). A value of $p$ less than 0.05 was considered significant and all statistical tests were two-tailed.

\section{Results}

Results are presented in Figs. 1 and 2, Tables 1 and 2. Mean difference and results of statistical analysis between periods are shown in Table 3.

\section{Hemodynamics}

The blood volume removed from the animals was $936 \pm$ $100 \mathrm{ml}(30 \mathrm{ml} / \mathrm{kg})$ and $909 \pm 94 \mathrm{ml}(29 \mathrm{ml} / \mathrm{kg})$ in the CTRL and ARDS group respectively $(p>0.05)$. CO (Figs. 1 and 2), mean arterial pressure and CVP decreased during the hemorrhage and recovered to baseline values during retransfusion (Table 3 ). The only exception was CVP in the ARDS group, which was slightly but significantly higher after retransfusion than pre-hemorrhage.

\section{Gas exchange, oxygen delivery and compliance}

In the CTRL group (Fig. 1), venous admixture decreased during hemorrhage and recovered to pre-hemorrhage values during retransfusion (Table 1). In the ARDS group (Fig. 2), shunt decreased during hemorrhage and recovered during re-transfusion, but did not fully return to pre-hemorrhage values (Table 2). In the CTRL group (Fig. 1), even if shunt changed, $\mathrm{PaO}_{2}: \mathrm{FiO}_{2}$, was similar across pre-hemorrhage, hemorrhage and retransfusion phases (Table 1). On the other hand, in the ARDS group (Fig. 2), $\mathrm{PaO}_{2}: \mathrm{FiO}_{2}$ varies inversely from shunt: increased during hemorrhage and did not recover completely during retransfusion (Table 2). The adjustment of $\mathrm{PaO}_{2}: \mathrm{FiO}_{2}$ for $\mathrm{SvO}_{2}$ did not change these results.

For both groups, $\mathrm{DO}_{2}$ varied in accordance with $\mathrm{CO}$. That is, $\mathrm{DO}_{2}$ decreased during hemorrhage and then recovered during retransfusion (CTRL group: Fig. 1; Table 1; ARDS group: Fig. 2; Table 2). The main determinants of $\mathrm{DO}_{2}$ were examined in the ARDS group. $\mathrm{CaO}_{2}$ did not change across the phases (Table 2), $\mathrm{Hb}$ remained stable across the phases and $\mathrm{SaO}_{2}$ increased during hemorrhage but did not recover during re-transfusion (Table 2).

For both groups, Crs increased during hemorrhage and recovered to pre-hemorrhage values during retransfusion (CTRL group: Fig. 1; Table 1; ARDS group: Fig. 2; Table 2). 


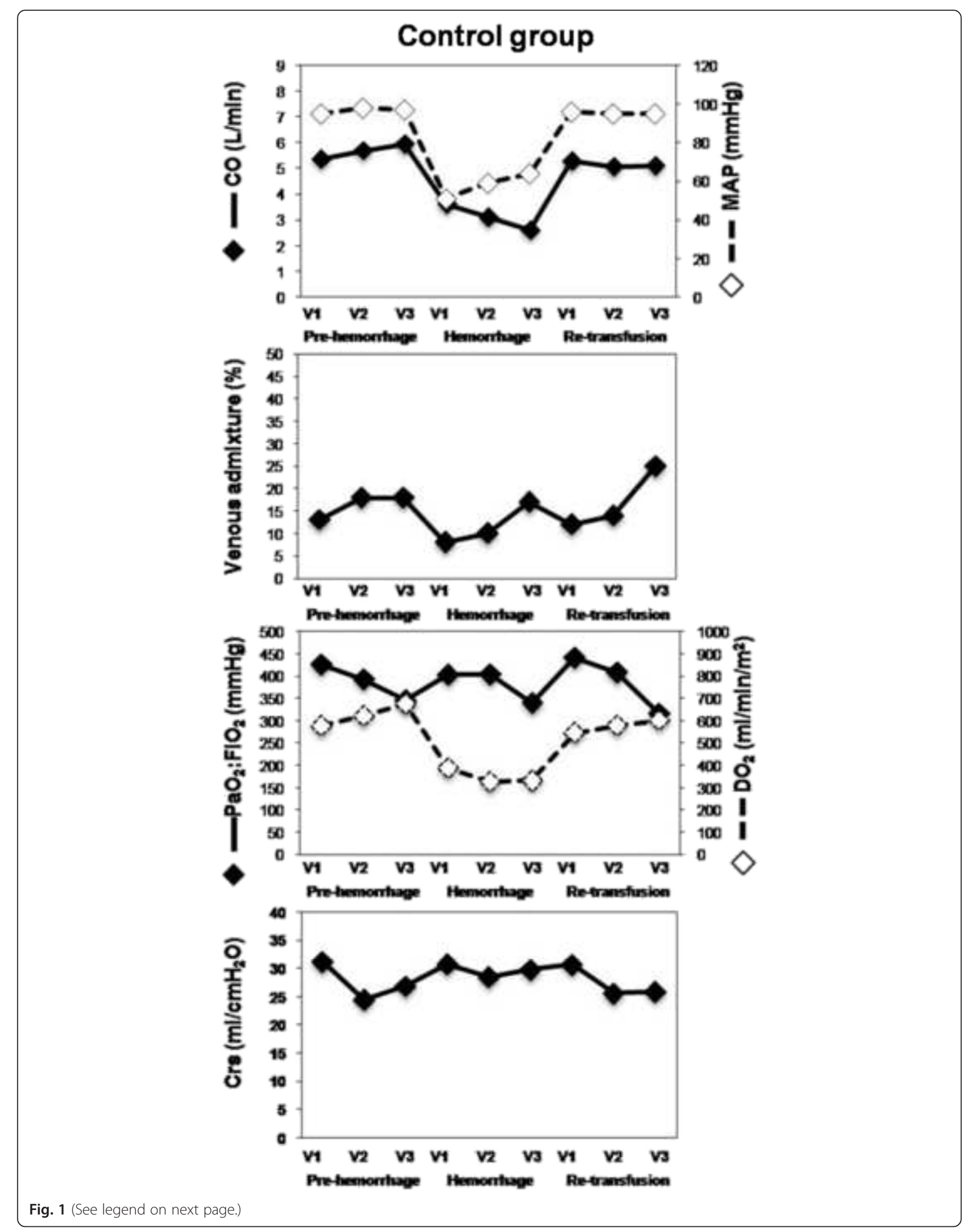


(See figure on previous page.)

Fig. 1 This figure shows the evolution of measured parameters during the experiment in the control group. All values are presented for each mode of ventilation (V1, V2, V3) in the successive phase of the experiment (Baseline, Hemorrhage, Re-transfusion). Crs, respiratory system compliance; $\mathrm{CO}$, cardiac output; DO2, oxygen delivery; MAP, mean arterial pressure $\mathrm{V} 1$, tidal volume: $10 \mathrm{ml}^{\mathrm{kg}}{ }^{-1}$ and respiratory rate: $15 \mathrm{~min}^{-1}$; $\mathrm{V} 2=$ tidal volume: $6 \mathrm{ml.kg}{ }^{-1}$ and respiratory rate: $25 \mathrm{~min}^{-1} ; \mathrm{V} 3$, tidal volume $6 \mathrm{ml}^{\mathrm{kg}}{ }^{-1}$ and respiratory rate: $15 \mathrm{~min}^{-1}$

\section{Impact of changes in ventilation settings on shunt in the ARDS group}

At baseline (pre-ARDS), shunt did not change with ventilation setting (V1 to V2 change $=5.12 \%(p=0.19)$, V2 to V3 change $=-1.83(p=0.61))$. After ARDS induction but before hemorrhage (pre-hemorrhage period), shunt was only affected by the change from V1 to V2 (change $=15.16, p=0.01$ ) but not from V2 to V3 (change $=3.10, \quad p=0.57$ ). After hemorrhage and retransfusion, there were no statistically significant differences in shunt values when ventilation was switched from V1 to V2 or from V2 to V3.

\section{Discussion}

In the present animal study, the authors investigated the effect of a decrease in $\mathrm{CO}$ through acute severe hypovolemia (with neither a pharmacologic intervention nor a mechanical procedure) on intra-pulmonary shunt in healthy and ARDS animals. Our analysis suggests that severe hypovolemia induced by acute hemorrhage is associated with a decrease in shunt and an increase in Crs in a pig model of ARDS. These changes were associated with improvements in $\mathrm{PaO}_{2}: \mathrm{FiO}_{2}$ only at high values of shunt (ARDS-like syndrome). The improvement in $\mathrm{PaO}_{2}: \mathrm{FiO}_{2}$ did not compensate for the decrease in $\mathrm{CO}$ and, as a consequence, $\mathrm{DO}_{2}$ decreased. To our knowledge, this is the first study showing the effects of acute hemorrhage on Crs in ARDS pig model.

In the present study, we observed that shunt and blood oxygenation were influenced by acute hemorrhage (shunt decrease) and retransfusion (shunt increase). Moreover, as during ARDS oxygenation is closely related to shunt $[21,22], \mathrm{PaO}_{2}: \mathrm{FiO}_{2}$ varied similarly to shunt. This relation between global perfusion and shunt has already been reported during a decrease and an increase in perfusion [4, 6-10]. However, the present study extends these results to demonstrate that this relation is associated with concomitant changes in respiratory system compliance and that the effects on $\mathrm{PaO}_{2}: \mathrm{FiO}_{2}$ are not observed for relatively moderate values of shunt.

The decrease in shunt during hemorrhage could be explained by several physiological mechanisms. Firstly, it may be related to a preferential decrease in the perfusion of low- and/or non-ventilated regions. Indeed, to have a significant impact on oxygenation, the decrease in lung perfusion must be larger in the shunted part of the lung than in other normal lung regions. In ARDS, shunt essentially resides in the injured areas of the lung, in which perfusion is already limited by microvascular obstruction [23], adaptative hypoxic vasoconstriction [24], and gravitational compression of vessels $[25,26]$. Secondly, in regions with lung injury, the impaired oxygenation and apparent "shunt" could also be explained by a decrease in pulmonary transit time in which the blood cannot be fully oxygenated because of increased red cell velocity $[27,28]$. Thus, when the animals are hemorrhaged and pulmonary flow reduced, the reduced flow velocity may be coupled to a more efficient blood oxygenation. Finally, changes in Crs may also have influenced $\mathrm{PaO}_{2}: \mathrm{FiO}_{2}$ as suggested by the significant correlation between the changes in $\mathrm{Cr}$ and the changes in $\mathrm{PaO}_{2}: \mathrm{FiO}_{2}$ observed in our analysis and reported in Fig. 3. As the increase in Crs decreased alveolar pressures it may result in an improvement in the perfusion of West zone II [29] that may have reduced shunt.

The other means by which shunt could be decreased is to recruit poorly or non-ventilated lung. However, in our analysis, the decrease in shunt and the concurrent improvement in $\mathrm{PaO}_{2}: \mathrm{FiO}_{2}$ remained significant whatever the $V_{T}$ value. This may be related to the fact that, during ARDS, pure shunt is predominant $[6,10]$ and small changes in $V_{T}$ value will not have a significant impact. Indeed, in the ARDS group, shunt significantly increased when $\mathrm{V}_{\mathrm{T}}$ was decreased from $10 \mathrm{ml} . \mathrm{kg}^{-1}$ (V1) to $6 \mathrm{ml} \cdot \mathrm{kg}^{-1}$ (V2) during normovolemia but not during hemorrhage, confirming that the circulatory state was the main determinant of the shunt during Hypovolemia (Fig. 1; Table 2). As well, although the calculated shunt in the CTRL group was overestimated (since the calculation of shunt at $\mathrm{FiO}_{2}$ lower than 100 \% represents venous admixture and not a true shunt [30]), the impact of bleeding on CTRL group $\mathrm{PaO}_{2}: \mathrm{FiO}_{2}$ was low, demonstrating that the circulatory state remains a determinant of the shunt only when lungs are affected by atelectasis.

However, even if gas exchange $\left(\mathrm{PaO}_{2}: \mathrm{FiO}_{2}\right)$ and $\mathrm{SaO}_{2}$ improved during hemorrhage, it does not result in better tissue oxygenation. Indeed, the improvement in $\mathrm{SaO}_{2}$ was not large enough to influence $\mathrm{CaO}_{2}$, due in part to a slight decrease in hemoglobin. As a consequence, the decrease in $\mathrm{CO}$ reduced $\mathrm{DO}_{2}$. However, as the initial study was not designed to measure tissue oxygenation abnormalities, the impact of this decrease of $\mathrm{DO}_{2}$ on other vital organs function have not be investigated in the present analysis. Nevertheless, our observation is relevant to 


\section{ARDS group}



120
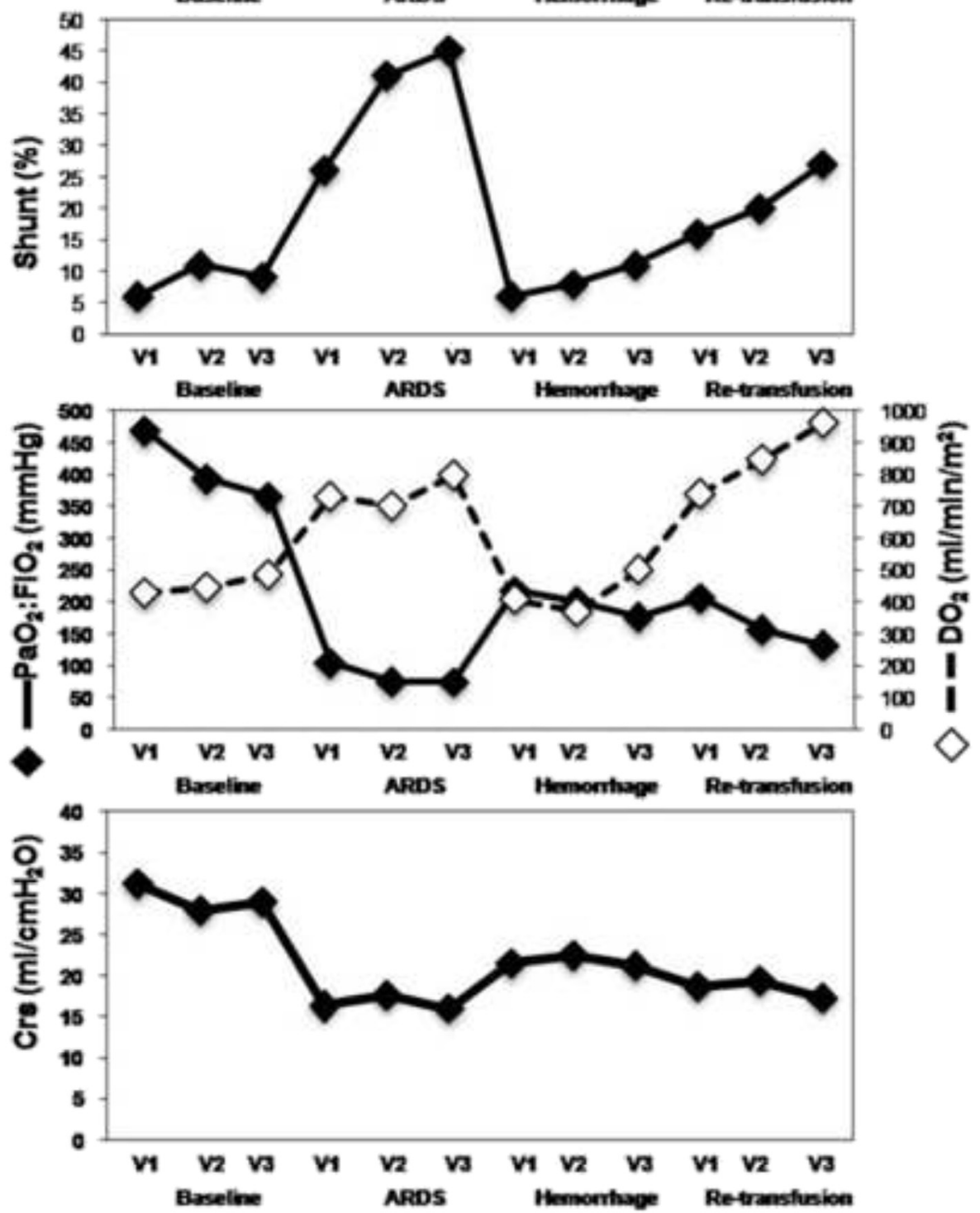

Fig. 2 This figure shows the evolution of measured parameters during the experiment in the ARDS group. All values are presented for each mode of ventilation (V1, V2, V3) in the successive phase of the experiment (Baseline, ARDS, Hemorrhage, Re-transfusion). Crs, respiratory system compliance; CO, cardiac output; DO2, oxygen delivery; MAP, mean arterial pressure; shunt, intrapulmonary shunt; $\mathrm{V1}$, tidal volume: 10 ml.kg ${ }^{-1}$ and respiratory rate: $15 \mathrm{~min}^{-1} ; \mathrm{V} 2=$ tidal volume: $6 \mathrm{ml}^{.} \mathrm{kg}^{-1}$ and respiratory rate: $25 \mathrm{~min}^{-1} ; \mathrm{V} 3$, tidal volume $6 \mathrm{ml}^{\mathrm{kg}} \mathrm{kg}^{-1}$ and respiratory rate: $15 \mathrm{~min}^{-1}$ 
Table 1 Hemodynamic, respiratory and oxygenation parameters during each mode of ventilation at each time point in the control group

\begin{tabular}{|c|c|c|c|c|c|c|c|c|c|c|c|c|}
\hline \multirow[b]{2}{*}{ Ventilation mode: } & \multicolumn{4}{|c|}{ Pre-hemorrhage Mean \pm SD } & \multicolumn{4}{|c|}{ Hemorrhage Mean \pm SD } & \multicolumn{4}{|c|}{ Retransfusion Mean \pm SD } \\
\hline & & & & & & & & & & & & \\
\hline Tidal volume:ml.k g-1 & VT:10 & VT:6 & VT:6 & $\begin{array}{l}\text { Average across } \\
\text { variants of ventilation }\end{array}$ & VT:10 & VT:6 & VT:6 & $\begin{array}{l}\text { Average across } \\
\text { variants of ventilation }\end{array}$ & VT:10 & VT:6 & VT:6 & $\begin{array}{l}\text { Average across } \\
\text { variants of ventilation }\end{array}$ \\
\hline $\begin{array}{l}\text { Respiratory rate: } \\
\text { breaths/min }\end{array}$ & RR: 15 & RR: 25 & RR: 15 & & RR: 15 & RR: 25 & RR: 15 & & RR: 15 & RR: 25 & RR: 15 & \\
\hline$\overline{\text { Cardiac output (I.min-1) }}$ & $5.4 \pm 1.4$ & $5.7 \pm 1.5$ & $6.0 \pm 1.9$ & $5.7 \pm 1.6$ & $3.6 \pm 0.8$ & $3.1 \pm 1.1$ & $2.6 \pm 1.6$ & $3.1 \pm 1$ & $5.3 \pm 1.7$ & $5.1 \pm 2.5$ & $5.1 \pm 2.6$ & $5.1 \pm 2.2$ \\
\hline Heart Rate (bpm) & $101 \pm 32$ & $100 \pm 26$ & $103 \pm 24$ & $101 \pm 27$ & $130 \pm 25$ & $154 \pm 50$ & $163 \pm 55$ & $150 \pm 46$ & $111 \pm 30$ & $114 \pm 25$ & $120 \pm 27$ & $115 \pm 26$ \\
\hline $\begin{array}{l}\text { Mean arterial pressure } \\
(\mathrm{mmHg})\end{array}$ & $95 \pm 13$ & $98 \pm 15$ & $97 \pm 14$ & $96.8 \pm 13.7$ & $51 \pm 15$ & $59 \pm 16$ & $64 \pm 13$ & $58.1 \pm 15.4$ & $96 \pm 10$ & $95 \pm 9$ & $95 \pm 10$ & $95.2 \pm 9.3$ \\
\hline $\begin{array}{l}\text { Central venous pressure } \\
(\mathrm{mmHg})\end{array}$ & $8 \pm 1$ & $7 \pm 1$ & $7 \pm 2$ & $8 \pm 1$ & $5 \pm 2$ & $5 \pm 3$ & $6 \pm 3$ & $5 \pm 3$ & $9 \pm 2$ & $7 \pm 3$ & $8 \pm 1$ & $8 \pm 2$ \\
\hline Veinous admixture (\%) & $13 \pm 4$ & $18 \pm 8$ & $18 \pm 9$ & $16 \pm 7$ & $8 \pm 4$ & $10 \pm 4$ & $17 \pm 14$ & $11 \pm 9$ & $12 \pm 4$ & $14 \pm 5$ & $25 \pm 12$ & $16 \pm 9$ \\
\hline $\mathrm{PaO2}: \mathrm{FiO} 2(\mathrm{mmHg})$ & $426 \pm 72$ & $393 \pm 92$ & $345 \pm 91$ & $388 \pm 89$ & $403 \pm 72$ & $404 \pm 87$ & $340 \pm 90$ & $385 \pm 84$ & $441 \pm 59$ & $408 \pm 54$ & $316 \pm 82$ & $395 \pm 79$ \\
\hline SVO2 (\%) & $78 \pm 8$ & $78 \pm 5$ & $76 \pm 8$ & $77 \pm 7.0$ & $60 \pm 12$ & $65 \pm 10$ & $64 \pm 15$ & $63 \pm 12$ & $82 \pm 5$ & $78 \pm 8$ & $77 \pm 6$ & $79 \pm 7$ \\
\hline $\begin{array}{l}\text { Global oxygen delivery } \\
(\mathrm{ml} \cdot \mathrm{min}-1 . \mathrm{m}-2)\end{array}$ & $575 \pm 160$ & $620 \pm 201$ & $674 \pm 305$ & $623 \pm 225$ & $388 \pm 99$ & $326 \pm 147$ & $333 \pm 159$ & $347 \pm 132$ & $544 \pm 228$ & $577 \pm 205$ & $601 \pm 258$ & $570 \pm 216$ \\
\hline $\begin{array}{l}\text { Respiratory system } \\
\text { compliance } \\
\left(\mathrm{ml} . \mathrm{cm} \mathrm{H}_{2} \mathrm{O}^{-1}\right)\end{array}$ & $31.2 \pm 3.6$ & $24.5 \pm 5.1$ & $26.9 \pm 4.6$ & $27.5 \pm 5.1$ & $30.8 \pm 5.4$ & $28.5 \pm 2.9$ & $29.8 \pm 7.4$ & $29.7 \pm 5.2$ & $30.7 \pm 4.1$ & $25.6 \pm 4.2$ & $25.9 \pm 4.3$ & $27.3 \pm 4.6$ \\
\hline
\end{tabular}


Table 2 Hemodynamic, respiratory and oxygenation parameters during each mode of ventilation at each time point in the ARDS group $(n=8)$

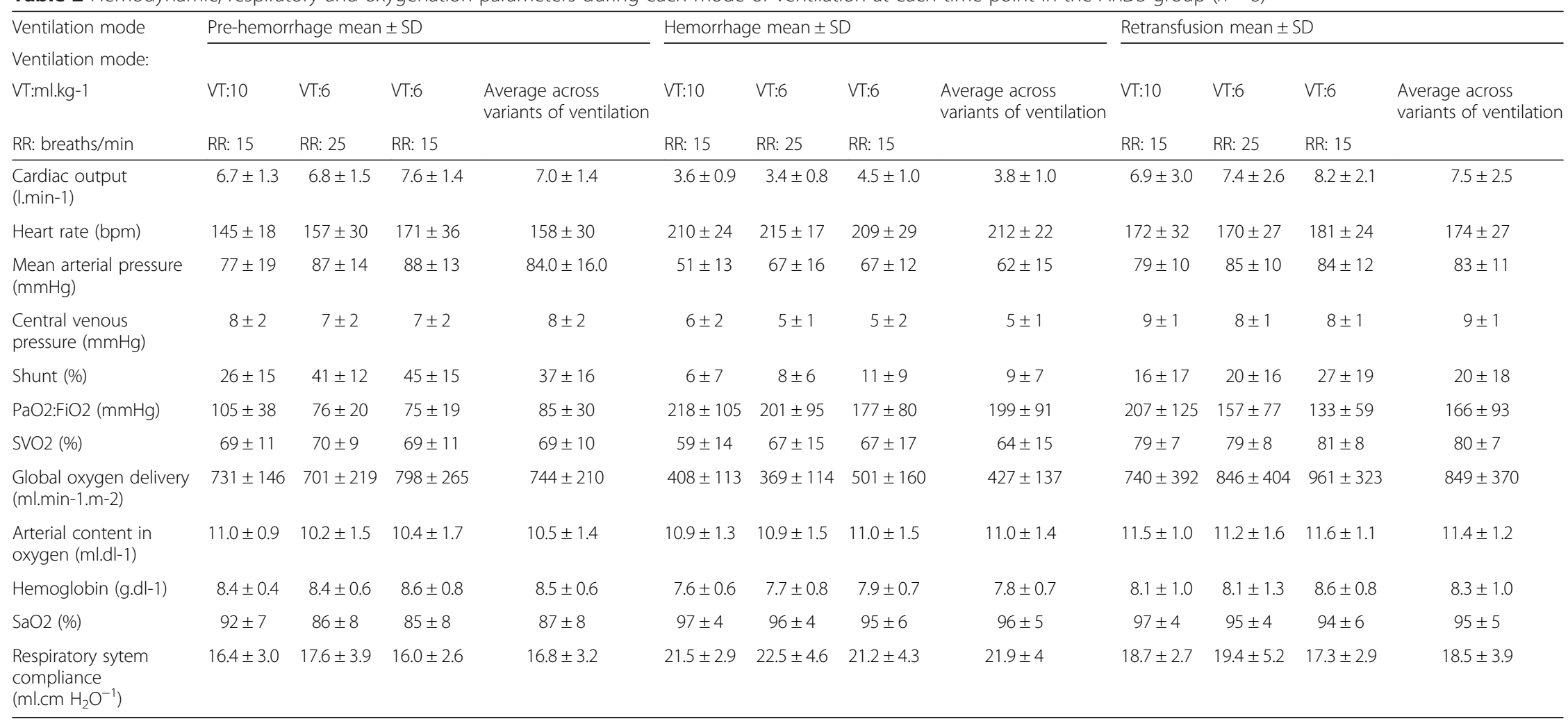


Table 3 Impact of hemorrhage and retransfusion on hemodynamic, respiratory and oxygenation parameters

\begin{tabular}{|c|c|c|c|c|c|c|c|}
\hline \multicolumn{2}{|l|}{ Phase } & \multicolumn{2}{|l|}{$\begin{array}{l}\text { Hemorrhage vs. } \\
\text { pre-hemorrhage }\end{array}$} & \multicolumn{2}{|c|}{ Retransfusion vs. hemorrhage } & \multicolumn{2}{|l|}{$\begin{array}{l}\text { Retransfusion vs. } \\
\text { pre-hemorrhage }\end{array}$} \\
\hline Parameter & Group & Mean difference \pm SE & $p$ & Mean difference \pm SE & $p$ & Mean difference \pm SE & $p$ \\
\hline \multicolumn{8}{|l|}{ Hemodynamic } \\
\hline \multirow[t]{2}{*}{ Cardiac output, I.min ${ }^{-1}$} & CTRL & $-2.6 \pm 0.3$ & $<0.001$ & $2.4 \pm 0.3$ & $<0.001$ & $-0.2 \pm 0.3$ & 0.48 \\
\hline & ARDS & $-3.2 \pm 0.4$ & $<0.001$ & $3.7 \pm 0.4$ & $<0.001$ & $0.5 \pm 0.4$ & 0.21 \\
\hline \multirow[t]{2}{*}{ Mean arterial pressure, $\mathrm{mmHg}$} & CTRL & $-36.7 \pm 3.1$ & $<0.001$ & $36.6 \pm 3.2$ & $<0.001$ & $-0.1 \pm 3.1$ & 0.98 \\
\hline & ARDS & $-22.4 \pm 4.0$ & $<0.001$ & $21.4 \pm 4.1$ & $<0.001$ & $-1.0 \pm 4.1$ & 0.80 \\
\hline \multirow[t]{2}{*}{ Central venous pressure, $\mathrm{mmHg}$} & CTRL & $-2.3 \pm 0.3$ & $<0.001$ & $2.9 \pm 0.4$ & $<0.001$ & $0.6 \pm 0.3$ & 0.09 \\
\hline & ARDS & $-2.2 \pm 0.3$ & $<0.001$ & $3.2 \pm 0.3$ & $<0.001$ & $1 \pm 0.3$ & 0.003 \\
\hline \multicolumn{8}{|l|}{ Respiratory system and oxygenation } \\
\hline Venous admixture, \% & CTRL & $-6.1 \pm 1.9$ & 0.002 & $4.9 \pm 1.9$ & 0.01 & $-1.2 \pm 1.8$ & 0.50 \\
\hline Shunt, \% & ARDS & $-28.5 \pm 3.5$ & $<0.001$ & $12.3 \pm 3.5$ & $<0.001$ & $-16.1 \pm 3.5$ & $<0.001$ \\
\hline \multirow[t]{2}{*}{$\mathrm{PaO}_{2}: \mathrm{FiO}_{2}, \mathrm{mmHg}$} & CTRL & $1.7 \pm 17.0$ & 0.92 & $13.2 \pm 17.2$ & 0.45 & $14.5 \pm 16.5$ & 0.37 \\
\hline & ARDS & $113.4 \pm 19.1$ & $<0.001$ & $-33.3 \pm 19.1$ & 0.09 & $80.2 \pm 19.1$ & $<0.001$ \\
\hline \multirow{2}{*}{$\begin{array}{l}\mathrm{PaO}_{2}: \mathrm{FiO}_{2} \text { adjusted for mixed } \\
\text { venous blood saturation, } \mathrm{mmHg}\end{array}$} & CTRL & $42.6 \pm 23.8$ & 0.08 & $-33.1 \pm 25.3$ & 0.20 & $9.4 \pm 16.2$ & 0.56 \\
\hline & ARDS & $125.7 \pm 19.2$ & $<0.001$ & $-71.3 \pm 22.5$ & 0.002 & $54.4 \pm 20.6$ & 0.01 \\
\hline \multirow[t]{2}{*}{ Global oxygen delivery, ml.min-1. $\mathrm{m}^{-2}$} & CTRL & $-290.8 \pm 37.0$ & $<0.001$ & $229.6 \pm 38.4$ & $<0.001$ & $-61.1 \pm 35.9$ & 0.09 \\
\hline & ARDS & $-316.9 \pm 49.8$ & $<0.001$ & $422.1 \pm 49.8$ & $<0.001$ & $105.3 \pm 49.8$ & 0.04 \\
\hline Arterial content in oxygen, $\mathrm{ml}^{-\mathrm{dl}^{-1}}$ & ARDS & $0.4 \pm 0.6$ & 0.51 & $0.5 \pm 0.6$ & 0.48 & $0.9 \pm 0.6$ & 0.18 \\
\hline Hemoglobin, g. $\mathrm{dl}^{-1}$ & ARDS & $-0.7 \pm 0.4$ & 0.08 & $0.5 \pm 0.4$ & 0.18 & $0.2 \pm 0.4$ & 0.65 \\
\hline Arterial blood saturation, \% & ARDS & $9.0 \pm 2.6$ & 0.004 & $-1.0 \pm 2.6$ & 0.76 & $8.0 \pm 2.6$ & 0.008 \\
\hline \multirow[t]{2}{*}{ Respiratory system compliance, ml.cm $\mathrm{H}_{2} \mathrm{O}^{-1}$} & CTRL & $2.5 \pm 0.9$ & 0.006 & $-2.6 \pm 0.9$ & 0.01 & $-0.1 \pm 0.9$ & 0.94 \\
\hline & ARDS & $5.1 \pm 1.0$ & $<0.001$ & $-3.3 \pm 1.0$ & 0.001 & $1.8 \pm 1.0$ & 0.07 \\
\hline
\end{tabular}

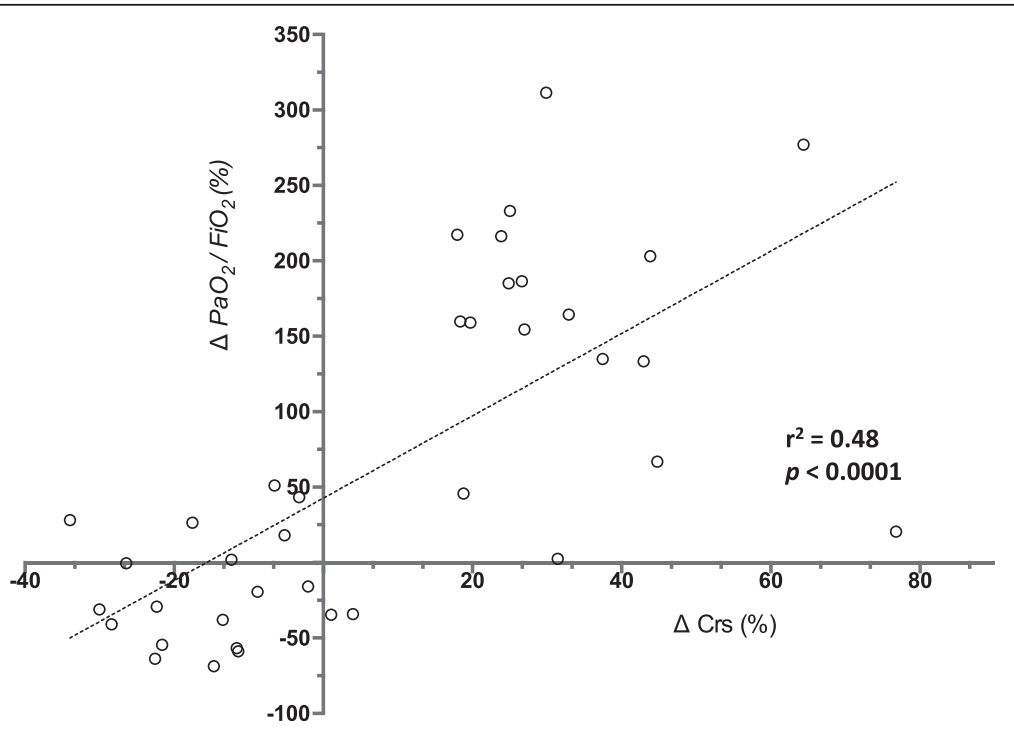

Fig. 3 This figure report the relation between the changes (\%) in $\mathrm{PaO}_{2}: \mathrm{FiO}_{2}$ and the changes (\%) in $\mathrm{Crs}$ after hemorrhage and retransfusion. The correlation coefficient $\left(r^{2}\right)$ describes how two variables vary together 
clinical settings, as it indicates that an improvement in $\mathrm{PaO}_{2}: \mathrm{FiO}_{2}$ and $\mathrm{SaO}_{2}$ can falsely mask a worsening in systemic oxygen delivery.

A key result in this study is the observed changes in Crs following blood volume shift (hemorrhage and retransfusion) (Table 3). An influence of blood volume on Crs has already been reported during blood volume decrease [12, 13] or increase [16], but previous studies reported conflicting results as they reported either a decrease $[5,31]$ or a stable $[14,15]$ Crs following hemorrhage. None of these studies investigated this effect during ARDS. One explanation for the inconsistency in previous results could be related to the variable and interrelated impact of blood volume on the total lung volume (including air, blood and tissue) and the participation of the microvascular network to the stiffness of the lung tissue. Indeed, considering the relation between pulmonary vascular pressure/filling and lung mechanical characteristics, various studies suggests that the pressurized pulmonary capillary network act as a tether for the lung tissue which may influence respiratory mechanics stability $[32,33]$.

This study acknowledges some limitations. First of all, the present report and analysis are based on previous experimentations [17] in which the main goal was far away from considering the impact of $\mathrm{CO}$ on intrapulmonary shunt. However, this secondary analysis of previously collected data is an ethical way to study further concepts without performing new experimentations and minimizing, by the way, the use of animals. Moreover, even if the design of the initial study was not specifically adapted to the aim of the present analysis, our results are in accordance with physiological laws and support previous works on this subject. Second, animals were ventilated without PEEP. Adding PEEP could have limited the development of atelectatic regions resulting in a model without significant shunt and decreased Crs, which could not allow investigating the specific effect of hemorrhage on these parameters. Consequently, we could not totally extrapolate the effects of hemorrhage on shunt and Crs in situations of ARDS ventilated with PEEP. However in patients with ARDS, even if high PEEP is used, the remaining hypoxemia is predominantly related to persistent shunt that could be influenced by the changes in CO. Third, our model of ARDS induced by a surfactant depletion method is a classical model of ARDS-like syndrome in animals resulting in reproducible and stable changes in physiological parameters similar to human ARDS [34]. However, this model is mainly characterized by atelectasis and less inflammatory lesions. Third, due to the design of the initial study [17], animals were ventilated with three successive ventilation modes. These changes in ventilatory settings could have influenced measured parameters. However, we used a mixed model ANOVA taking into account the effect of ventilation mode. Moreover, when we analyzed the impact of changes in ventilatory settings on shunt in the ARDS group, the mode of ventilation affected shunt only in the prehemorrhage period and between $\mathrm{V} 1: \mathrm{V}_{\mathrm{T}}: 10 \mathrm{ml} \cdot \mathrm{kg}^{-1}$, RR: $15 \mathrm{~min}^{-1}$ and V2: $\mathrm{V}_{\mathrm{T}}: 6 \mathrm{ml} . \mathrm{kg}-1$, RR: $25 \mathrm{~min}^{-1}$ but not in other period nor other change in ventilation mode. Therefore, the ventilation mode used in this study does not seem to influence significantly the measured parameters. Fourth, the translation of this physiological model in a clinical perspective is not straightforward: our model of acute and severe hemorrhage is not strictly equivalent to a progressive hypovolemia, as could be obtained by diuretic for example. However, our results consolidate the hypothesis that decrease in blood volume may influence respiratory system characteristics, especially when these characteristics are already altered. Moreover it emphasizes that the influence of a decrease in blood volume on $\mathrm{SaO}_{2}$ or $\mathrm{PaO}_{2}: \mathrm{FiO}_{2}$ may be at the expense of global oxygen delivery. Our model may be more closely encountered for example during the institution or the weaning of extracorporeal membrane oxygenation (ECMO) where large and acute changes in circulating blood volume may influence respiratory system characteristics. Finally, the compensatory release of catecholamine associated with the acute severe hemorrhage model may have influenced our observation. Indeed, catecholamine increase pulmonary vascular resistance [35] which may have amplified the decrease in pulmonary shunt observed during hemorrhage.

\section{Conclusion}

Our observations show that there is an impact of blood volume on respiratory system characteristics and oxygenation parameters during ARDS. Indeed, we observed that an acute hemorrhage results in a decrease in shunt with a parallel improvement in arterial oxygenation. Moreover, after hemorrhage, Crs improves. Our observations illustrate the link between physiologic mechanisms and clinical observations and may explain why in clinical practice a rapid modest improvement in lung compliance and/or a large improvement in oxygenation parameters in patients with ARDS may not necessarily reflect an improvement in patient condition but rather may be related to an acute decrease in transpulmonary blood flow. Our analysis thus strengthens the importance to integrate the circulatory condition in the analysis of the state of the respiratory system. However, the caveats of the study (use of a model not replicable in clinical activity; lack of data on the impact of oxygen delivery on clinical outcome) do not allow having a reliable take-home message for the clinical management of ARDS.

\section{Ethics approval}

The study was approved by the Ethics Committee for Animal Research at the University Medical Centre and by the Cantonal Veterinary Office of Geneva, Switzerland 
(No 31.1.1043/3127/1). Animals received respectful care in accordance with the Guide for the Care and Use of Laboratory Animals (Institute of Laboratory Animal Resources, 1996).

\section{Consent for publication \\ "Not applicable".}

\section{Availability of data and material}

The data supporting our results are presented within the article.

\section{Availability of data and materials Data are available upon request.}

\section{Abbreviations}

ABG: arterial blood gas; ARDS: acute respiratory distress syndrome; $\mathrm{CaO}_{2}$ : arterial oxygen content; $\mathrm{CcO}_{2}$ : pulmonary capillary oxygen content; CO: cardiac output: Crs: respiratory system compliance; CTRL group: no intervention; $\mathrm{CVO}_{2}$ : mixed venous oxygen content; CVP: central venous pressure; $\mathrm{DO}_{2}$ : global oxygen delivery; $\mathrm{Hb}$ : hemoglobin; $\mathrm{PaO}_{2}: \mathrm{FiO}_{2}$ : arterial oxygenation; PEEP: positive end-expiratory pressure; Qs: shunt flow; Qs/ Qt: Intrapulmonary shunt; Qt: represents the systemic blood flow; RR: respiratory rate; $\mathrm{SaO}_{2}$ : oxygen saturation (arterial blood oxygen saturation; $\mathrm{SVO}_{2}$ : mixed venous blood oxygen saturation; $\mathrm{V}_{T}$ : tidal volume.

\section{Competing interests}

The authors declare that they have no competing interests.

\section{Authors' contributions}

NS conceive the study, analyze and interpret the results, write the paper; RG participate to the interpretation of the results and to the writing of the paper; DSC performed the statistical analysis and participate to the writing of the paper; CUW, performed the data acquisition and participate to the writing of the paper; KB conceived the original and the actual study, analyze and interpret the results and participate to the writing of the paper. All authors read and approved the final manuscript.

\section{Acknowledgments}

"Not applicable".

\section{Source of funding}

This study was funded by an institutional grant from the Anesthesiology, Pharmacology and Intensive Care Department of the Geneva University Hospital (APSI 06-07). The authors declare no conflicts of interest for this study. No reprints will be ordered.

\section{Author details \\ ${ }^{1}$ Intensive Care Unit, University Hospitals of Geneva, Geneva, Switzerland. ${ }^{2}$ University of Geneva, University Medical Center, Geneva, Switzerland. ${ }^{3}$ Division of Clinical Epidemiology (Biostatistics), University Hospitals of Geneva, Geneva, Switzerland. ${ }^{4}$ Department of Physiology and Pharmacology, Division of Anaesthesiology and Intensive Care, Karolinska Institute, Stockholm, Sweden. ${ }^{5}$ Geneva Hemodynamic Research Group, Geneva, Switzerland. ${ }^{6}$ Department of Anesthesiology, Pharmacology and Intensive Care, Service of Adult Intensive Care, Geneva University Hospital, Rue Gabrielle-Perret-Gentil 4, 1205 Genève, Switzerland.}

Received: 14 October 2015 Accepted: 14 April 2016 Published online: 26 April 2016

\section{References}

1. Briel M, Meade M, Mercat A, Brower RG, Talmor D, Walter SD, et al. Higher vs lower positive end-expiratory pressure in patients with acute lung injury and acute respiratory distress syndrome: systematic review and meta-analysis. JAMA. 2010;303:865-73.
2. Ventilation with lower tidal volumes as compared with traditional tidal volumes for acute lung injury and the acute respiratory distress syndrome. The Acute Respiratory Distress Syndrome Network. N Engl J Med. 2000;342(18):1301-8.

3. Smith G, Cheney FW, Winter PM. The effect of change in cardiac output on intrapulmonary shunting. Br J Anaesth. 1974;46:337-42.

4. Breen PH, Schumacker PT, Sandoval J, Mayers I, Oppenheimer L, Wood LD. Increased cardiac output increases shunt: role of pulmonary edema and perfusion. J Appl Physiol. 1985;59:1313-21.

5. Fulton RL, Fischer RP. Pulmonary changes due to hemorrhagic shock resuscitation with isotonic and hypertonic saline. Surgery. 1974;75:881-91.

6. Lynch JP, Mhyre JG, Dantzker DR. Influence of cardiac output on intrapulmonary shunt. J Appl Physiol. 1979;46:315-21.

7. Light RB, Ali J, Breen P, Wood LD. The pulmonary vascular effects of dopamine, dobutamine, and isoproterenol in unilobar pulmonary edema in dogs. J Surg Res. 1988;44:26-35.

8. Fredén F, Cigarini I, Mannting F, Hagberg A, Lemaire F, Hedenstierna G. Dependence of shunt on cardiac output in unilobar oleic acid edema. Distribution of ventilation and perfusion. Intensive Care Med. 1993;19:185-90.

9. Lovering AT, Romer LM, Haverkamp HC, Pegelow DF, Hokanson JS, Eldridge MW. Intrapulmonary shunting and pulmonary gas exchange during normoxic and hypoxic exercise in healthy humans. J Appl Physiol. 2008;104:1418-25.

10. Dantzker DR, Lynch JP, Weg JG. Depression of cardiac output is a mechanism of shunt reduction in the therapy of acute respiratory failure. Chest. 1980;77:636-42.

11. Matamis D, Lemaire F, Harf A, Teisseire B, Brun-Buisson C. Redistribution of pulmonary blood flow induced by positive end-expiratory pressure and dopamine infusion in acute respiratory failure. Am Rev Respir Dis. 1984;129:39-44.

12. Cahill JM, Byrne JJ. Ventilatory mechanics in hypovolemic shock. J Appl Physiol. 1964;19:679-82.

13. Proctor HJ, Moss GS, Homer LD, Litt BD. Changes in lung compliance in experimental hemorrhagic shock and resuscitation. Ann Surg. 1969;169:82-92.

14. Sprung J, Mackenzie CF, Green MD, O'Dwyer J, Barnas GM. Chest wall and lung mechanics during acute hemorrhage in anesthetized dogs. J Cardiothorac Vasc Anesth. 1997;11:608-12.

15. Martins MA, Zin WA, Younes RN, Negri EM, Sakae RS, Lin CA, et al. Respiratory system mechanics in guinea pigs after acute hemorrhage: role of adrenergic stimulation. Crit Care Med. 1990;18:515-9.

16. Hauge $A, B \varnothing G$, Waaler $B A$. Interrelations between pulmonary liquid volumes and lung compliance. J Appl Physiol. 1975;38:608-14.

17. Wiklund CU, Morel DR, Orbring-Wiklund H, Romand J-A, Piriou V, Teboul J-L, et al. Influence of tidal volume on pulse pressure variations in hypovolemic ventilated pigs with acute respiratory distress-like syndrome. Anesthesiology. 2010;113:630-8.

18. Brochard L. Intrinsic (or auto-) positive end-expiratory pressure during spontaneous or assisted ventilation. Intensive Care Med. 2002;28:1552-4.

19. Lachmann B, Robertson B, Vogel J. In vivo lung lavage as an experimental model of the respiratory distress syndrome. Acta Anaesthesiol Scand. 1980;24:231-6.

20. West JB. State of the art: ventilation-perfusion relationships. Am Rev Respir Dis. 1977;116:919-43.

21. Gattinoni L, Pesenti A. The concept of "baby lung". Intensive Care Med. 2005;31(6):776-84

22. Dantzker DR, Brook CJ, Dehart P, Lynch JP, Weg JG. Ventilation-perfusion distributions in the adult respiratory distress syndrome. Am Rev Respir Dis. 1979;120:1039-52

23. Tomashefski JF, Davies P, Boggis C, Greene R, Zapol WM, Reid LM. The pulmonary vascular lesions of the adult respiratory distress syndrome. Am J Pathol. 1983;112:112-26.

24. Brimioulle S, Julien V, Gust R, Kozlowski JK, Naeije R, Schuster DP. Importance of hypoxic vasoconstriction in maintaining oxygenation during acute lung injury. Crit Care Med. 2002;30:874-80.

25. Pelosi P, D'Onofrio D, Chiumello D, Paolo S, Chiara G, Capelozzi VL, et al. Pulmonary and extrapulmonary acute respiratory distress syndrome are different. Eur Respir J Suppl. 2003;42:48s-56s.

26. Pelosi P, Brazzi L, Gattinoni L. Prone position in acute respiratory distress syndrome. Eur Respir J. 2002;20:1017-28.

27. Granger WM, Miller DA, Ehrhart IC, Hofman WF. The effect of blood flow and diffusion impairment on pulmonary gas exchange: a computer model. Comput Biomed Res. 1987;20:497-506.

28. Hopkins SR, Belzberg AS, Wiggs BR, McKenzie DC. Pulmonary transit time and diffusion limitation during heavy exercise in athletes. Respir Physiol. 1996;103:67-73 
29. West JB, Dollery CT, Naimark A. Distribution of blood flow in isolated lung; relation to vascular and alveolar pressures. J Appl Physiol. 1964;19:713-24.

30. Ab L. Nunn's applied respiratory physiology sixth edition. Philadelphia: Elsevier/Butterworth Heinemann; 2005.

31. Kakvan M, Masuoka S, Simeone FA. Pulmonary function in irreversible hemorrhagic shock in dogs. Surg Forum. 1971;22:29-31.

32. Peták F, Habre W, Hantos Z, Sly PD, Morel DR. Effects of pulmonary vascular pressures and flow on airway and parenchymal mechanics in isolated rat lungs. J Appl Physiol 1985. 2002;92:169-78.

33. Albu G, Habre W, Fontao F, Morel DR, Petak F. The contribution of the pulmonary microvascular pressure in the maintenance of an open lung during mechanical ventilation. Respir Physiol Neurobiol. 2007;157:262-9.

34. Muellenbach RM, Kredel M, Zollhoefer B, Bernd Z, Johannes A, Kuestermann $J$, et al. Acute respiratory distress induced by repeated saline lavage provides stable experimental conditions for 24 hours in pigs. Exp Lung Res. 2009:35:222-33.

35. Barman SA. Effect of catecholamines on pulmonary circulation at elevated vascular tone. J Appl Physiol. 1995;78:1452-8.

Submit your next manuscript to BioMed Central and we will help you at every step:

- We accept pre-submission inquiries

- Our selector tool helps you to find the most relevant journal

- We provide round the clock customer support

- Convenient online submission

- Thorough peer review

- Inclusion in PubMed and all major indexing services

- Maximum visibility for your research

Submit your manuscript at www.biomedcentral.com/submit
Biomed Central 